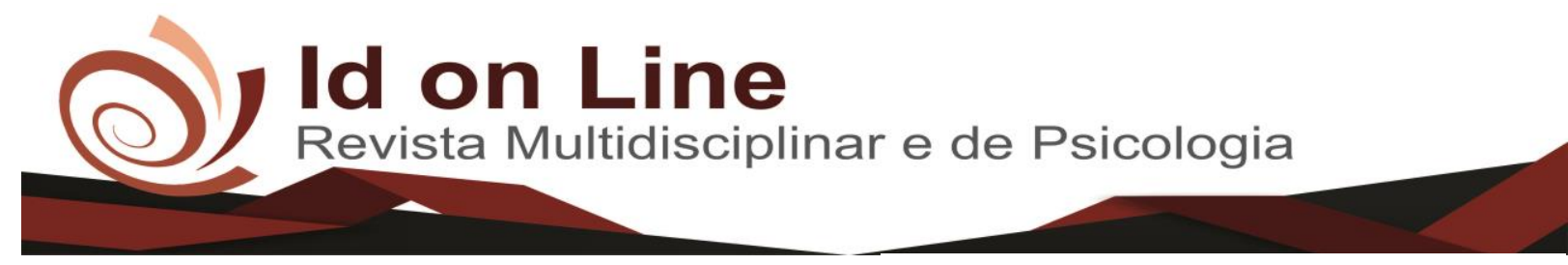

Artigo

\title{
Compras Públicas e Apoio Logístico na UNIVASF: Um Estudo Bibliométrico.
}

\author{
Nathallia Barbosa Alencar Maial; Tâmara Rodrigues Coelho²; Bruno Cezar Silva ${ }^{3}$
}

Resumo: O presente artigo aborda o tema de compras públicas e apoio logístico na Universidade Federal do Vale do São Francisco UNIVASF, tendo como justificativa da proposta de execução do objetivo, que se encontrou essencialmente na necessidade de conhecer como são os procedimentos licitatórios. Para descrever as inovações da gestão pública no contexto geral, foi realizada um estudo bibliométrico pela Revista de Administração de Empresas RAE, um estudo documental através dos artigos publicados. No primeiro momento, o estudo bibliométrico, será realizado um estudo sistemático nos artigos, mas ainda vamos nas consultas pela Internet, e em distintas fontes que tem fácil acesso ao público em geral, que abordam do tema estudado, objetivando compor o referencial teórico.

Palavras-chave: Licitações. Gestão Pública. Estudo bibliométrico.

\section{Public Purchases and Logistic Support in UNIVASF: A Bibliometric Study.}

Abstract: This article deals with public procurement and logistical support at the Federal University of the São Francisco Valley, UNIVASF, as a justification for the proposed implementation of the objective, which was essentially found in the need to know how the bidding procedures are. To describe the innovations of public management in the general context, a bibliometric study was carried out by the Journal of Business Administration RAE, a documentary study through the published articles. In the first moment, the bibliometric study, will be carried out a systematic study in the articles, but still we go in the consultations by Internet, and in different sources that have easy access to the general public, that approach of the studied subject, aiming to compose the theoretical reference.

Keywords: Tenders. Public administration. Bibliometric study.

\footnotetext{
${ }^{1}$ Pós-Graduanda em Gestão Pública (UNIVASF). Bacharel em Administração (UNIVASF).

Email: nnathi.barbosa@gmail.com;

2 Pós-Graduanda em Gestão Pública (UNIVASF). Bacharel em Administração de empresas (FACAPE).

Email: tamara_r.coelho16@hotmail.com;

${ }^{3}$ Graduação em Direito pela Universidade do Estado da Bahia - UNEB, Especialização em Direito Processual Civil pela FIJ e Mestrado em Gestão de Políticas Públicas e Segurança Social pela Universidade Federal do Recôncavo da Bahia - UFRB. Professor nas Especializações em Gestão Pública e Gestão Pública Municipal no programa de Pós Graduação da SEAD/Univasf e na Graduação em Administração Pública da SEAD/Univasf. E-mail: Bruno.cezar@univasf.edu.br.
} 


\section{Introdução}

O desenvolvimento da gestão pública tem como condição necessária para atingir certo propósito, que é essencial à garantia de alcance dos objetivos e resultados dos programas e ações governamentais.

A licitação é um procedimento administrativo formal, de execução prescrita pelos órgãos e/ou entidades governamentais.

A licitação não é um procedimento novo na gestão pública, ela faz parte do cotidiano de uma organização pública. Seja como instrumento de levantamento de demanda itens permanentes e por não permanentes, das indispensabilidades por novas licitações ou pregões vigentes.

\section{Caracterização da organização}

\section{Histórico e Constituição da UNIVASF}

Conforme verificado no site da UNIVASF (2014), a Fundação Universidade Federal do Vale do São Francisco (UNIVASF) é uma instituição de ensino superior pública, mantida pelo Governo Federal do Brasil, que iniciou suas atividades acadêmicas em 2004. Situada nos estados de Pernambuco, Piauí e Bahia, é uma das universidades federais do país a estar presente em três estados, com campi nas cidades de Petrolina - PE, Juazeiro - BA, São Raimundo Nonato - PI, Senhor do Bonfim - BA e Paulo Afonso - BA.

Sua área de abrangência: legitimada pela Lei complementar n. ${ }^{\circ} 113$, de 19 de setembro de 2001, tendo o semiárido nordestino e o Vale do São Francisco, como referências.

De acordo com leitura feita no site G1.Globo: Petrolina e região (2014), a UNIVASF recebia aproximadamente $\mathrm{R} \$ 2$ milhões por mês e passou a receber cerca de $\mathrm{R} \$ 4$ milhões. Julianeli Tolentino afirma, "recebemos além de recursos do Ministério da Educação, do Ministério da Saúde, por causa do Hospital Universitário". 


\section{PROPLADI - Pró-Reitoria de Planejamento e Desenvolvimento Institucional A}

Segundo o site da Propladi (2018) é um setor responsável por sistematizar e operacionalizar processos e procedimentos internos de alocação de recursos orçamentários e materiais, visando atender necessidades dos diversos setores, proporcionando condições para o desenvolvimento das atividades de ensino, pesquisa, extensão e administrativas; subsidiar e conduzir o planejamento estratégico da instituição, primando pelo envolvimento de todos os segmentos da comunidade acadêmica (desenvolvimento participativo) na identificação e superação dos desafios institucionais.

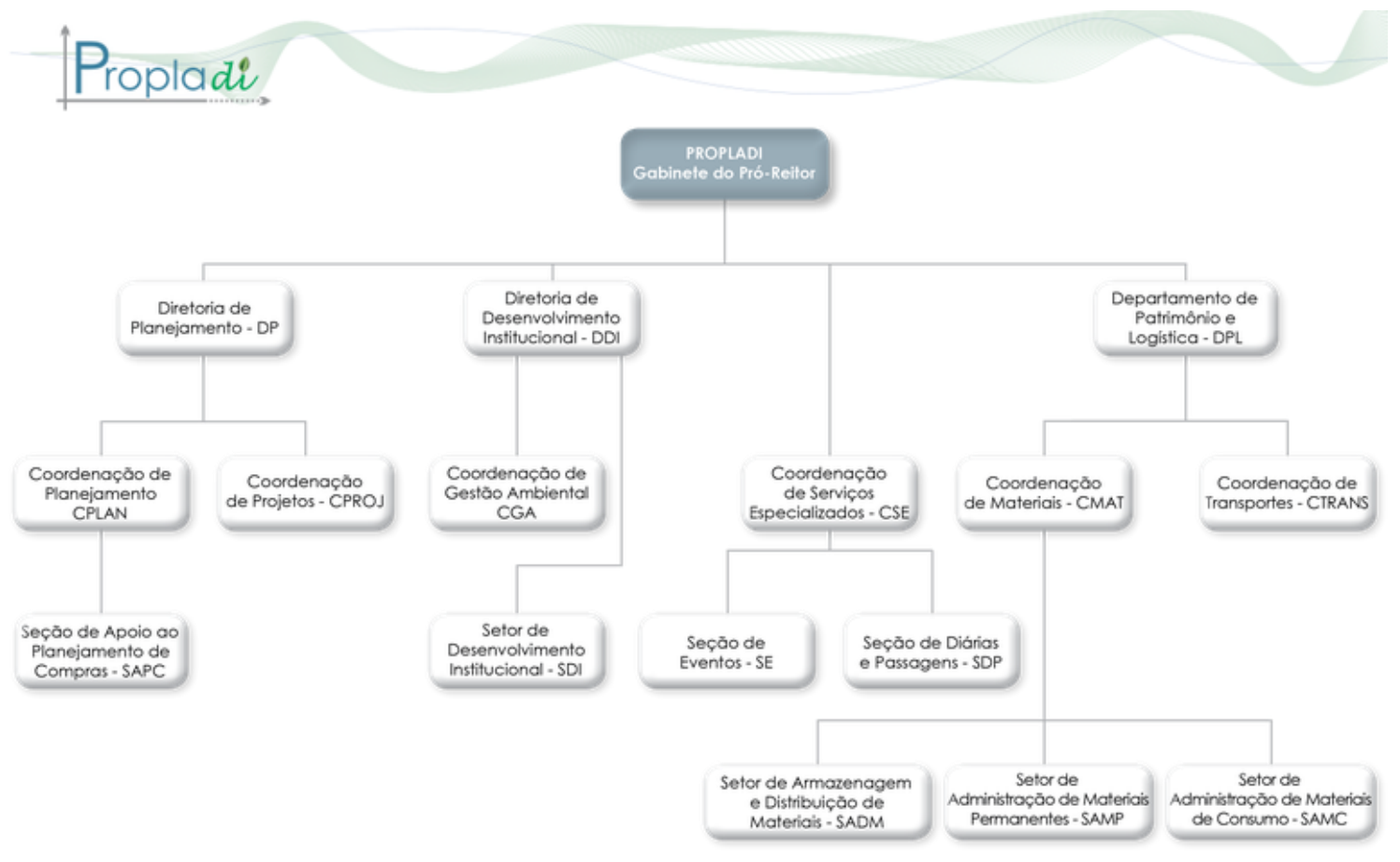

Figura 1. Organograma

Fonte: PROPLADI (2018).

Diretoria de Departamento de Patrimônio e Logística (DPL/ PROPLADI), responsável por 03 (três) coordenações: 
- CSE (Coordenação de Serviços Especializados): passagens e diárias, agendamento de veículos, agendamento complexo multieventos e auditório da biblioteca, colações de grau e placas da formatura;

- CMAT (Coordenação de Materiais): solicitações de mobiliário, materiais de consumo (expediente, tonner, água mineral, gás de cozinha) e outros materiais permanentes;

- CTRANS (Coordenação de Transportes): utilização de veículos oficiais, liberação de senhas de abastecimento, manutenções nos veículos, e demais solicitações que envolverem veículos oficiais.

Na Diretoria de Departamento de Patrimônio e Logística - DPL/ PROPLADI, que é composta por 01 (um) Diretor e outros 15 (quinze) servidores, 30 (trinta) funcionários terceirizados e 02 (dois) estagiários, distribuídos em 03 (três) Coordenações:

- Gabinete da Diretoria: 02 (dois) servidores (Diretor e Assistente em Administração) e 01 (um) estagiário;

○ Coordenação de Serviços Especializados - CSE: 05 (cinco) servidores e 02 (dois) funcionários terceirizados;

○ Coordenação de Materiais - CMAT: 07 (sete) servidores, 10 (dez) funcionários terceirizados e 01 (um) estagiário;

○ Coordenação de Transportes - CTRANS: 02 (dois) servidores e 18 (dezoito) funcionários terceirizados.

\section{Referencial Teórico}

\section{Licitação}

Os sistemas de informação estão transformando o ambiente de organização públicas, propiciando aos cidadãos e aos gestores públicos informações rápidas e precisas sobre os mais variados aspectos de interesse social.

Os sistemas de informação em organizações públicas em geral são estruturados de formas semelhantes. Pois produzem serviços e produtos para atender à demanda da sociedade e dos mercados. 
No caput da norma estão dispostos os fundamentos legais da competência, no TCU (2010),

Licitação é procedimento administrativo formal em que a Administração Pública convocada, por meio de condições estabelecidas em ato próprio (edital ou convite), empresas interessadas na apresentação de propostas para o oferecimento de bens e serviços. Licitação não será sigilosa, exceto quanto ao conteúdo das propostas até serem conhecidas. São públicos e acessíveis aos cidadãos os atos do respectivo processo. Será efetuada sempre no local onde se situar a repartição interessada, salvo por motivo de interesse público, devidamente justificado.

A Lei n. ${ }^{\circ} 8.666$ 1993, ao regulamentar o artigo $1 .^{\circ}$, inciso XXI da Constituição Federal, estabelece normas gerais sobre licitações e contratos administrativos pertinentes a obras, serviços, inclusive de publicidade, compras, alienações e locações no âmbito dos Poderes da União, dos Estados, do Distrito Federal e dos Municípios.

De acordo com essa Lei, o TCU (2010), afirma,

a celebração de contratos com terceiros na Administração Pública deve ser necessariamente precedida de licitação, ressalvadas as hipóteses de dispensa e de inexigibilidade de licitação. É direito do administrativo perante a Administração, sem prejuízo de outros que lhe sejam assegurados, de formular alegações e de apresentar documentos antes da decisão, os quais serão objeto de consideração pelo órgão competente, consoante o disposto no artigo 3..$^{\circ}$, inciso III, da Lei n. ${ }^{\circ} 9.784$, de 29 de janeiro de 1999, que regula o processo administrativo no âmbito da Administração Federal. Com base nesse diploma legal, é vedado à Administração recusar imotivadamente o recebimento de documentos, devendo o servidor orientar o interessado quanto ao suprimento de eventuais falhas.

Tabela 1 - Licitação e significados

\begin{tabular}{|c|c|}
\hline \multicolumn{2}{|l|}{ LICITAÇÃO } \\
\hline Licitação dispensada & $\begin{array}{l}\text { Modalidade de contratação por meio da qual a Lei de Licitações desobriga a } \\
\text { Administração do dever de licitar. Abarca as alienações de bens móveis e } \\
\text { imóveis previstas no art.17 da Lei } n^{\circ} 8.666 / 1993 \text {; }\end{array}$ \\
\hline Licitação dispensável & $\begin{array}{l}\text { Modalidade de contratação por meio da qual a Lei de Licitações desobriga a } \\
\text { Administração do dever de licitar. Compreende exclusivamente as situações } \\
\text { previstas no art. } 24 \text { da Lei n }{ }^{\circ} 8.666 / 1993 \text {; }\end{array}$ \\
\hline Licitação deserta & $\begin{array}{l}\text { Caracteriza-se quando não comparecem licitantes ao procedimento licitatório } \\
\text { realizado; }\end{array}$ \\
\hline Licitação fracassada & $\begin{array}{l}\text { Caracteriza-se quando há participantes no processo licitatório, mas todos são } \\
\text { inabilitados ou todas as propostas são desclassificadas; }\end{array}$ \\
\hline Licitações simultâneas & $\begin{array}{l}\text { Aquelas com objetos similares e que ocorram em intervalos inferiores ou } \\
\text { iguais a trinta dias; }\end{array}$ \\
\hline Licitações sucessivas & $\begin{array}{l}\text { Aquelas com objetos similares, em que o edital subsequente tenha data anterior } \\
\text { a } 120 \text { dias após o término do contrato resultante da licitação antecedente; }\end{array}$ \\
\hline $\begin{array}{lll}\text { Licitação de } & \text { alta } \\
\text { complexidade técnica } & \end{array}$ & $\begin{array}{l}\text { Aquela que envolve alta especialização, como fator de extrema relevância para } \\
\text { garantir a execução do objeto a ser contratado, ou que possa comprometer a } \\
\text { continuidade da prestação de serviços públicos essenciais. }\end{array}$ \\
\hline
\end{tabular}

Fonte: Manual de Licitações e Contratos (2010). 


\section{Normas gerais da licitação}

Tabela 2 - Normas da licitação

\begin{tabular}{|l|l|}
\hline O que licitar & $\begin{array}{l}\text { Compras de bens, execução de obras, prestação de serviços, alienações e locações } \\
\text { devem ser contratadas por meio de licitações públicas, exceto nos casos previstos na } \\
\text { Lei n. } 8.666 / 1993, \text { e alterações posteriores. }\end{array}$ \\
\hline Por que licitar & $\begin{array}{l}\text { Estabelece a Constituição Federal, artigo 37, inciso XXI, a obrigatoriedade de licitar } \\
\text { para a Administração Pública. Objetiva a licitação permitir que a Administração } \\
\text { contrate aqueles que reúnam as condições necessárias para satisfação do interesse } \\
\text { público, levando em consideração especialmente aspectos relacionados à capacidade } \\
\text { técnica e econômico-financeira da empresa licitante, à qualidade do produto e ao valor } \\
\text { do objeto. O procedimento licitatório busca assegurar a todos os interessados igualdade } \\
\text { de condições no fornecimento de bens, execução de obras ou prestação de serviços para } \\
\text { a Administração Pública. }\end{array}$ \\
\hline $\begin{array}{l}\text { Quem deve } \\
\text { licitar }\end{array}$ & $\begin{array}{l}\text { Estão sujeitos à regra de licitar, além dos órgãos integrantes da Administração Direta, } \\
\text { as Autarquias, as Fundações Públicas, as Empresas Públicas, as Sociedades de } \\
\text { Economia Mista, os fundos especiais e demais entidades controladas direta ou } \\
\text { indiretamente pela União, Estados, Distrito Federal e Municípios. }\end{array}$ \\
\hline Como licitar & $\begin{array}{l}\text { Uma vez definido o que se contratar, é necessário estimar o valor total do objeto, } \\
\text { mediante realização de pesquisa de mercado. Deve-se ainda verificar se há previsão de } \\
\text { recursos orçamentários para o pagamento da despesa e se esta se encontra em } \\
\text { conformidade com a Lei de Responsabilidade Fiscal. }\end{array}$ \\
\hline
\end{tabular}

Fonte: Manual de Licitações e Contratos (2010).

\section{Termos e significados}

Tabela 3 - Termos na licitação

\begin{tabular}{|c|c|}
\hline $\begin{array}{l}\text { Adimplemento de obrigação } \\
\text { contratual }\end{array}$ & $\begin{array}{l}\text { Entrega de bem, realização de obra, prestação de serviço ou de parcela } \\
\text { destes, ou qualquer outro evento contratual que venha requerer a emissão } \\
\text { de documento de cobrança; }\end{array}$ \\
\hline Agente público & $\begin{array}{l}\text { Pessoa física incumbida, definitiva ou transitoriamente, do exercício de } \\
\text { alguma função estatal; }\end{array}$ \\
\hline Bens e serviços comuns & $\begin{array}{l}\text { Aqueles cujos padrões de desempenho e qualidade possam ser concisa e } \\
\text { objetivamente definidos no objeto do edital, por meio de especificações } \\
\text { usuais de mercado; }\end{array}$ \\
\hline Caução & $\begin{array}{l}\text { Modalidade de garantia oferecida em dinheiro ou em títulos da dívida } \\
\text { pública, por licitantes ou contratados, para assegurar o fiel cumprimento } \\
\text { de obrigações assumidas em procedimentos licitatórios e em contratos } \\
\text { celebrados pela Administração Pública; }\end{array}$ \\
\hline Comissão & $\begin{array}{l}\text { Criada pela Administração com a função de receber, examinar e julgar } \\
\text { todos os documentos e procedimentos relativos às licitações e ao } \\
\text { cadastramento de licitantes, em número mínimo de três membros; }\end{array}$ \\
\hline Compra & $\begin{array}{l}\text { Toda aquisição remunerada de bens para fornecimento de uma só vez ou } \\
\text { parceladamente; }\end{array}$ \\
\hline $\begin{array}{l}\text { Obra, serviço ou compra de } \\
\text { grande vulto }\end{array}$ & $\begin{array}{l}\text { Aquela cujo valor estimado é superior a } 25 \text { vezes o limite estabelecido } \\
\text { na alínea c do inciso I do art. } 23 \text { da Lei no } 8.666 / 1993 \text { (R\$ } \\
37.500 .000,00) \text {; }\end{array}$ \\
\hline
\end{tabular}




\begin{tabular}{|c|c|}
\hline Concedente & $\begin{array}{l}\text { Partícipe responsável pela transferência de recursos financeiros } \\
\text { destinados à execução de objeto de convênio; }\end{array}$ \\
\hline Contratante & $\begin{array}{l}\text { Órgão ou entidade da Administração Pública Direta e Indireta da União } \\
\text { que pactua a execução de programa, projeto, atividade ou evento, por } \\
\text { intermédio de instituição financeira federal (mandatária) mediante } \\
\text { celebração de contrato de repasse, ou seja, órgão ou entidade signatária } \\
\text { de instrumento contratual; }\end{array}$ \\
\hline Contratado & $\begin{array}{l}\text { Pessoa física ou jurídica signatária de instrumento contratual com a } \\
\text { Administração Pública, na condição de fornecedor de bens, executor de } \\
\text { obra ou prestador de serviço; }\end{array}$ \\
\hline Contrato & $\begin{array}{l}\text { Todo e qualquer ajuste entre órgãos ou entidades da Administração } \\
\text { Pública e particulares, em que haja um acordo de vontades para a } \\
\text { formação de vínculo e a estipulação de obrigações recíprocas, seja qual } \\
\text { for a denominação utilizada; }\end{array}$ \\
\hline Contrato de repasse & $\begin{array}{l}\text { Todo e qualquer instrumento administrativo por meio do qual a } \\
\text { transferência dos recursos financeiros se processa por intermédio de } \\
\text { instituição ou agente financeiro público federal, atuando como } \\
\text { mandatário da União; }\end{array}$ \\
\hline Convenente & $\begin{array}{l}\text { Órgão ou entidade da Administração Pública Direta e Indireta, de } \\
\text { qualquer esfera de governo, ou entidade privada sem fins lucrativos, com } \\
\text { o qual a Administração Federal pactua a execução de programa, projeto/ } \\
\text { atividade ou evento mediante celebração de convenio, ou seja, participe } \\
\text { de um convênio; }\end{array}$ \\
\hline Convênio & $\begin{array}{l}\text { Convênio é todo e qualquer instrumento formal que discipline a } \\
\text { transferência de recursos da União para estados, municípios, Distrito } \\
\text { Federal ou entidades particulares, com vistas à execução de programas } \\
\text { de trabalho, projeto/atividade ou evento de interesse recíproco, em } \\
\text { regime de mútua colaboração; }\end{array}$ \\
\hline Dispensa de licitação & $\begin{array}{l}\text { Modalidade de contratação direta por meio da qual a Administração está } \\
\text { desobrigada de realizar procedimento licitatório. Na dispensa de } \\
\text { licitação, a competição, embora possível, não é obrigatória, em razão de } \\
\text { outros princípios que regem a atividade administrativa; }\end{array}$ \\
\hline Edital & $\begin{array}{l}\text { Lei interna da licitação. Documento que enumera todas as condições que } \\
\text { devem ser cumpridas pela Administração e pelos licitantes num processo } \\
\text { licitatório; }\end{array}$ \\
\hline Empreitada integral & $\begin{array}{l}\text { Quando se contrata determinado empreendimento na integralidade, que } \\
\text { compreenda todas as etapas da obra, serviço e instalações necessárias, } \\
\text { sob inteira responsabilidade do contratado até a respectiva entrega ao } \\
\text { contratante em condições de entrada em operação, atendidos os } \\
\text { requisitos técnicos e legais para utilização em condições de segurança } \\
\text { estrutural e operacional, bem assim com as características adequadas às } \\
\text { finalidades da contratação; }\end{array}$ \\
\hline Empreitada por preço global & $\begin{array}{l}\text { Regime de execução em que se contrata a obra ou o serviço por preço } \\
\text { certo e total; }\end{array}$ \\
\hline Empreitada por preço unitário & $\begin{array}{l}\text { Regime de execução em que se contrata a obra ou o serviço por preço } \\
\text { certo de unidades determinadas; }\end{array}$ \\
\hline Entidade & Unidade de atuação dotada de personalidade jurídica; \\
\hline Equipe de apoio & $\begin{array}{l}\text { Grupo de pessoas, detentoras de conhecimento técnico sobre o objeto } \\
\text { licitado, para prestar auxílio ao pregoeiro; }\end{array}$ \\
\hline Etapa & $\begin{array}{l}\text { Cada uma das partes em que se divide o fornecimento do bem, execução } \\
\text { da obra ou prestação do serviço, em relação aos prazos ou cronogramas } \\
\text { contratuais; }\end{array}$ \\
\hline Execução direta & $\begin{array}{l}\text { Forma de execução realizada pelos órgãos e entidades da Administração, } \\
\text { pelos próprios meios; }\end{array}$ \\
\hline Execução indireta & $\begin{array}{l}\text { Contratada com terceiros sob os regimes empreitada por preço global, } \\
\text { empreitada por preço unitário, tarefa ou empreitada integral; }\end{array}$ \\
\hline
\end{tabular}




\begin{tabular}{|c|c|}
\hline Executor & Responsável direto pela execução do objeto contratado; \\
\hline Fiança bancária & $\begin{array}{l}\text { Modalidade de garantia oferecida por licitantes ou contratados, com a } \\
\text { interveniência de instituição bancária, para assegurar o fiel cumprimento } \\
\text { de obrigações assumidas nos procedimentos licitatórios e nos contratos } \\
\text { celebrados pela Administração Pública; }\end{array}$ \\
\hline Inexigibilidade de licitação & $\begin{array}{l}\text { Modalidade de contratação direta por meio da qual a Administração está } \\
\text { desobrigada de realizar o procedimento licitatório, por inviabilidade de } \\
\text { competição; }\end{array}$ \\
\hline Insumos & $\begin{array}{l}\text { Mão de obra, materiais e equipamentos utilizados na produção de } \\
\text { materiais e serviços; }\end{array}$ \\
\hline Interveniente & $\begin{array}{l}\text { Órgão da Administração Pública Direta e Indireta de qualquer esfera de } \\
\text { governo, ou entidade privada que participa de convênio para manifestar } \\
\text { consentimento ou assumir obrigações em nome próprio; }\end{array}$ \\
\hline Licitação & $\begin{array}{l}\text { Procedimento administrativo formal em que a Administração Pública } \\
\text { convoca, mediante condições estabelecidas em ato convocatório, } \\
\text { empresas interessadas na apresentação de propostas para o oferecimento } \\
\text { de bens e serviços; }\end{array}$ \\
\hline Licitante & $\begin{array}{l}\text { Pessoa física ou jurídica que adquire o edital e seus elementos } \\
\text { constitutivos/anexos e participa da licitação; }\end{array}$ \\
\hline Licitante vencedora & $\begin{array}{l}\text { Pessoa física ou jurídica habilitada no procedimento licitatório e } \\
\text { detentora da proposta mais vantajosa, a quem for adjudicado o objeto da } \\
\text { licitação; }\end{array}$ \\
\hline Objetivo da licitação & $\begin{array}{l}\text { Garantia da observância do princípio constitucional da isonomia e da } \\
\text { seleção da proposta mais vantajosa para a Administração; }\end{array}$ \\
\hline Obra & $\begin{array}{l}\text { Toda construção, reforma, fabricação, recuperação ou ampliação de bem } \\
\text { público, realizada diretamente pela Administração ou de forma indireta, } \\
\text { por intermédio de terceiro contratado por meio de licitação, de acordo } \\
\text { com a legislação vigente; }\end{array}$ \\
\hline Ordenador de despesa & $\begin{array}{l}\text { Toda e qualquer autoridade de cujos atos resultarem emissão de } \\
\text { empenho, autorização de pagamento, suprimento ou dispêndio de } \\
\text { recursos da Administração; }\end{array}$ \\
\hline Órgão & Unidade de atuação que integra a estrutura da Administração Pública; \\
\hline Órgão licitador & Aquele que realiza a licitação; \\
\hline $\begin{array}{l}\text { Planilha de custos e formação } \\
\text { de preços }\end{array}$ & $\begin{array}{l}\text { Documento que o licitante apresenta, contendo o detalhamento dos } \\
\text { custos que compõem seus preços; }\end{array}$ \\
\hline Preço & Valor que se atribui a determinado bem ou serviço; \\
\hline Pregão & $\begin{array}{l}\text { Modalidade de licitação em que a disputa pelo fornecimento de bens ou } \\
\text { serviços comuns é feita em sessão pública, por meio de propostas de } \\
\text { preços escritas e lances verbais ou via internet; }\end{array}$ \\
\hline Pregão Presencial & $\begin{array}{l}\text { Modalidade de licitação em que a disputa pelo fornecimento de bens ou } \\
\text { serviços comuns é feita em sessão pública, com a presença dos } \\
\text { interessados, por meio de propostas escritas e lances verbais; }\end{array}$ \\
\hline Pregão eletrônico & $\begin{array}{l}\text { Modalidade de licitação em que a disputa pelo fornecimento de bens ou } \\
\text { serviços comuns é feita em sessão pública, com a utilização de recursos } \\
\text { de tecnologia da informação. No pregão eletrônico, o oferecimento de } \\
\text { propostas e lances é feito exclusivamente pela internet. }\end{array}$ \\
\hline Pregoeiro & $\begin{array}{l}\text { Servidor designado para, em procedimento licitatório na modalidade } \\
\text { pregão, credenciar os interessados, receber as propostas e os documentos } \\
\text { de habilitação, examinar as propostas, conduzir os procedimentos } \\
\text { relativos à fase de lances, analisar a aceitabilidade dos preços, habilitar } \\
\text { os licitantes e adjudicar o objeto ao vencedor; }\end{array}$ \\
\hline Projeto básico & $\begin{array}{l}\text { Descrição detalhada do objeto a ser contratado, dos serviços a serem } \\
\text { executados, sua frequência e periodicidade, características do pessoal, } \\
\text { materiais e equipamentos a serem fornecidos e utilizados, procedimentos } \\
\text { a serem seguidos, cuidados, deveres, disciplina, gestão da qualidade, } \\
\text { informações a serem prestadas e controles a serem adotados; }\end{array}$ \\
\hline
\end{tabular}




\begin{tabular}{|c|c|}
\hline Projeto executivo & $\begin{array}{l}\text { Conjunto dos elementos necessários e suficientes à execução completa } \\
\text { da obra, de acordo com as normas pertinentes da Associação Brasileira } \\
\text { de Normas Técnicas (ABNT); }\end{array}$ \\
\hline Salário normativo & $\begin{array}{l}\text { Salário estabelecido para determinadas categorias profissionais, } \\
\text { pertinentes à execução do contrato, por acordo, convenção ou dissídio } \\
\text { coletivo de trabalho; }\end{array}$ \\
\hline Serviço & $\begin{array}{l}\text { Toda atividade destinada a obter determinada utilidade de interesse para } \\
\text { a Administração, tais como: demolição, conserto, instalação, montagem, } \\
\text { operação, conservação, reparação, adaptação, manutenção, transporte, } \\
\text { locação de bens, publicidade, seguro ou trabalhos técnico-profissionais; }\end{array}$ \\
\hline Seguro-garantia & $\begin{array}{l}\text { Modalidade de garantia oferecida por licitantes ou contratados, por meio } \\
\text { de empresa seguradora, para assegurar o fiel cumprimento de obrigações } \\
\text { assumidas em procedimentos licitatórios e em contratos celebrados pela } \\
\text { Administração Pública; }\end{array}$ \\
\hline Serviços contínuos & $\begin{array}{l}\text { Aqueles serviços auxiliares, necessários à Administração para o } \\
\text { desempenho de suas atribuições, cuja interrupção possa comprometer a } \\
\text { continuidade de suas atividades e cuja contratação deva estender-se por } \\
\text { mais de um exercício financeiro; }\end{array}$ \\
\hline Tarefa & $\begin{array}{l}\text { Regime de execução em que se ajusta mão-de-obra para pequenos } \\
\text { trabalhos por preço certo, com ou sem fornecimento de materiais; }\end{array}$ \\
\hline Termo de aditamento & $\begin{array}{l}\text { Instrumento que tenha por objetivo a modificação do convênio já } \\
\text { celebrado, vedada a alteração do objeto aprovado; }\end{array}$ \\
\hline Termo de cooperação & $\begin{array}{l}\text { Instrumento por meio do qual é ajustada a transferência de crédito de } \\
\text { órgão da Administração Pública Federal Direta, autarquia, fundação } \\
\text { pública, ou empresa estatal dependente, para outro órgão ou entidade } \\
\text { federal da mesma natureza; }\end{array}$ \\
\hline Termo de referência & $\begin{array}{l}\text { Documento que deve conter elementos capazes de propiciar avaliação } \\
\text { do custo pela Administração, diante de orçamento detalhado, definição } \\
\text { dos métodos, estratégia de suprimento, valor estimado em planilhas de } \\
\text { acordo com o preço de mercado, cronograma físico-financeiro, se for o } \\
\text { caso, critério de aceitação do objeto, deveres do contratado e do } \\
\text { contratante, procedimentos de fiscalização e gerenciamento do contrato, } \\
\text { prazo de execução e sanções, de forma clara, concisa e objetiva. }\end{array}$ \\
\hline
\end{tabular}

Fonte: Manual de Licitações e Contratos (2010).

\section{Modalidades de licitação}

As cinco modalidades de licitação previstas legalmente são: Convite; Tomada de preços; Concorrência; Concurso; Leilão.

Todas previstas na Lei n. ${ }^{\circ}$ 8.666/1993, e o pregão também, na Lei n. ${ }^{\circ}$ 10.5020/2002.

Existe a modalidade de consultas, além dessas, que é aplicável às agências reguladoras. 


\section{Metodologia}

Para descrever as inovações da gestão pública no contexto geral, foi realizada um estudo bibliométrico pela Revista de Administração de Empresas - RAE, um estudo documental através dos artigos publicados. No primeiro momento, o estudo bibliométrico, será realizado um estudo sistemático nos artigos, mas ainda vamos nas consultas pela Internet, e em distintas fontes que tem fácil acesso ao público em geral, que abordam do tema estudado, objetivando compor o referencial teórico.

A escolha da metodologia de estudo está ampara pelos argumentos propostos por LIMA, apud PRITCHARD, 1969 “bibliometria é uma apreciação quantitativa de variáveis da fala, é o tratamento quantitativo (matemático e estatístico) das características e do procedimento do informe registrado. Ainda segundo LIMA (1984), os estudos e técnicas bibliométricas têm sido usados com sucesso em uma grande variedade de aplicações, embora a maioria dos estudos seja descritivos, compilações de dados e estatísticos relativamente simples. Todavia estes estudos são interessantes e podem levar a resultados até certo ponto surpreendentes. Um dos maiores problemas até agora tem sido o laborioso e difícil levantamento de dados, as limitações e dificuldades da coleta de dados e do tratamento manual da base de dados.

\section{Resultados e Discussões}

Diante do estudo, foi verificado no $1 .^{\circ}$ (primeiro) artigo publicado antes da Lei da Licitação 8.666 de 21 de junho de 1993, foi propagado no ano de 1986 na Revista de Administração de Empresas - RAE, com o título de "Os critérios de julgamento das licitações".

Relacionando ao ano em que mais foi publicado artigos sobre a Gestão Pública no modo geral, apresentam-se os dados na Tabela 4. 
Tabela 4. Número de artigos por ano de publicação

\begin{tabular}{c|c}
\hline Ano de publicação & $\mathbf{N}^{\mathbf{0}}$ de Artigos \\
\hline 1986 & 01 \\
1993 & 01 \\
1995 & 02 \\
1999 & 01 \\
2002 & 02 \\
2003 & 02 \\
2005 & 01 \\
2006 & 01 \\
2007 & 01 \\
2008 & 01 \\
2011 & 01 \\
2012 & 01 \\
2013 & 01 \\
2018 & 01 \\
\hline Total & $\mathbf{1 7}$ \\
\hline
\end{tabular}

Fonte: Dados da Pesquisa (2018).

Como analisado na Tabela 4, fica visível que teve mais produção nos anos de 1995, 2002 e 2002.

Em 1995, o artigo "Os contratos de gestão: contradições e caminhos da administração pública" que explica os instrumentos de implementação de uma administração por objetivos na repartição, tendo como objetivo à característica de serviços e o poder das organizações. O “Contrato de gestão no estado de São Paulo: o caso das empresas estatais não-financeiras", os resultados indicaram um balanço relativamente positivo com relação à experiência do governo paulista, a necessidade de estabelecimento de contrapartidas e o reforço do contrato de gestão a partir de uma maior autonomia empresarial e da garantia de mobilização dos recursos acordados. Robles (1995) afirma, as contrapartidas englobam um sistema de recompensas positivas e negativas com base no desempenho empresarial, referenciando ao acordado nos contratos de eliminação de controles governamentais paralelos e superpostos.

Em 2002, existente na administração pública brasileira a proposição A inovação, BARACCHINI (2002) conclui que é admissível assegurar que estão acontecendo modificações no padrão das políticas públicas brasileiras, especialmente na esfera local de governo. Tendo como exemplo, variações conseguem ser alcançadas, como parte de um procedimento de idealização de recentes aspectos de gestão pública e que averiguou a verdade a partir de atos 
que inova no fornecimento de atividades por governanças subnacionais no país. Com o propósito que se pretende alcançar, debater os pontos de vista no intuito de introduzir algumas mudanças sob o entendimento de um gestor público, será exposto um caso prático contemplado pelo Programa Gestão Pública e Cidadania, em 1996 que explana o acontecido dessas modificações. Já no outro artigo O legado de Celso Daniel para a gestão pública, FARAH (2002) afirma que o entendimento de Celso em relação a precisão de articulação entre o realizar e o refletir. $\mathrm{O}$ desenvolvimento e o crescimento da administração permaneceriam a serviço dos princípios morais, um dos acordos políticos.

Em 2003, o artigo Administração pública nas revistas especializadas Brasil, 1995-2002, que almeja debater a administração pública como campo de ensinamentos e estudos. PACHECO (2003) afirma que, o artigo averigua a eficiência brasileira na esfera de estudo em administração pública, usando como alicerce os artigos publicados entre 1995 e 2002 nas revistas especializadas. Sucede movimentos passados concretizados em relação a área, que estendiam a mostrar como indispensável vulnerabilidade a natureza construtiva da produção em administração pública. Declara tal qual característica pertinente à área, dada a estrutura do propósito de estudo, fundamentalmente que foi posto em prática. Determina outras razões que fazem jus a discussão e estudo para desempenhar o avanço a pesquisa na área, como: a habilidade de pesquisadores a se auto-referirem, a dissolução do conteúdo e a perfilhação acrítica de teorias estudadas em diversas disciplinas. Aborda, além disso, a adequação da área, apresentada as precisões de estudo em relação a governos e governança, da mesma maneira de o desenvolvimento que defende o progresso e as transformações públicas. Na gestão pública no Brasil: notícias do teatro de operações, fala das propostas é indicar possíveis pontos de aproximação entre os estudos organizacionais e gestão pública em uma perspectiva institucionalista, já que a sensação é de que há espaço para mais comunicação entre ambos (SCHOMMER, 2003).

Com essas abordagens, a Tabela 5 considera a temática de acordo com o tipo de governo. 
Tabela 5. Número de artigos publicados por período de governo

\begin{tabular}{c|c|c}
\hline Períodos de governo & Presidentes & $\mathbf{N}^{\mathbf{0}}$ de Artigos \\
\hline $1985-1990$ & José Sarney & 01 \\
$1993-1994$ & Itamar Franco & 01 \\
$1995-1998$ & Fernando Henrique Cardoso & 02 \\
$1999-2002$ & Fernando Henrique Cardoso & 03 \\
$2003-2006$ & Luís Inácio Lula da Silva & 04 \\
$2007-2010$ & Luís Inácio Lula da Silva & 02 \\
$2011-2014$ & Dilma Rousseff & 03 \\
$2016-2018$ & Michel Temer & 01 \\
\hline
\end{tabular}

Fonte: Dados da Pesquisa (2018).

\section{Considerações Finais}

É de suma importância o planejamento de todo o processo da licitação no contexto, para atender as demandas da instituição e o processo não ser torne tão extenso.

No ambiente dos serviços públicos vem se constituindo como mecanismo contemporâneo, que assim, contribui para a incentivar de forma positiva, obviamente, as organizações públicas no relativamente a sua locação frente ao mercado, tanto de serviços, como de produtos.

Do que foi abordado, constatamos que para a gestão pública apresenta como fator compatível como uma nova visão, através da gestão estratégica, em função das expectativas da sociedade ao qual se insere. Dessa maneira, podemos sinalizar que a gestão estratégica é o modo pelo qual a organização põe em ação a estratégica disponível para atingir os objetivos, a missão, visão e valores da organização como todo, para caracterizar assim, e chegar a sua visão no futuro.

\section{Referências}

ANDRÉ, Maristela Afonso de. A efetividade dos contratos de gestão na reforma do estado. 1999. Disponível em: <http://bibliotecadigital.fgv.br/ojs/index.php/rae/article/view/37833/36592>. Acesso em: 20 março 2018. 
ANDRÉ, Maristela Afonso de. Contratos de gestão: contradições e caminhos da administração pública. $1995 . \quad$ Disponível em: <http://bibliotecadigital.fgv.br/ojs/index.php/rae/article/view/38196/36940>. Acesso em: 21 março 2018.

BARACCHINI, Sabrina Addison. A inovação presente na administração pública brasileira. 2002. Disponível em: <http://bibliotecadigital.fgv.br/ojs/index.php/rae/article/view/37589/36342>. Acesso em: 19 março 2018.

BRANDãO, L. E. T.; BASTIAN-PINTO, C. de L.; GOMES, L. L.; SALGADO, M. S. Incentivos governamentais em PPP: uma análise por opções reais. 2012. Disponivel em: <http://rae.fgv.br/sites/rae.fgv.br/files/artigos/10.1590_s0034-75902012000100002.pdf>. Acesso em: 16 março 2018.

BRASIL. Lei das licitações, por Lei n. ${ }^{\circ}$ 8.666, DE 21JUNHO DE 1993. Planalto. 1993. Disponível em: <http://www.planalto.gov.br/ccivil_03/Leis/L8666cons.htm>. Acesso em: 19 março 2018.

CKAGNAZAROFF, Ivan Beck. As pedras e as flores do caminho: os percursos da gestão pública no 2006.2 Drasil. 2 Disponível <http://bibliotecadigital.fgv.br/ojs/index.php/rae/article/view/37028/35800 >. Acesso em: 16 fevereiro 2018.

FARAH, Marta Ferreira Santos. O legado de Celso Daniel para a gestão pública. 2002. Disponível em: <http://bibliotecadigital.fgv.br/ojs/index.php/rae/article/view/37590/36343>. Acesso em: 20 fevereiro 2018.

G1.GLOBO.COM. Reitor avalia os 10 anos da Univasf no Vale do São Francisco. 2014. Disponível em: $<$ http://g1.globo.com/pe/petrolina-regiao/noticia/2014/10/reitor-avalia-os-10-anos-da-univasf-novale-do-sao-francisco.html>. Acesso em: 15 fevereiro 2018.

KEINERT, Tania Margarete Mezzomo. Reforma administrativa nos anos 90: o caso da prefeitura municipal de São Paulo. 1993. Disponível em: <http://bibliotecadigital.fgv.br/ojs/index.php/rae/article/view/38439/37179>. Acesso em: 20 fevereiro 2018.

LAIA, Marconi Martins de; CUNHA, Maria Alexandra Veigas Cortez da; NOGUEIRA, Antonio Roberto Ramos; MAZZON, José Afonso. Políticas de Governo Eletrônico no Brasil: Contexto, Gestão de Tic e Resultados. 2011. Disponível em: <http://bibliotecadigital.fgv.br/ojs/index.php/rae/article/view/31005/29819>. Acesso em: 16 fevereiro 2018.

LIMA, Regina Célia Montenegro de. Estudo bibliométrico: análise de citações no periódico scientometrics. 1984. Disponível em: <revista.ibict.br>. Acesso em: 20 abril 2018.

MOTTA, Paulo Roberto de Mendonça. O estado da arte da Gestão Pública. 2013. Disponível em: <http://bibliotecadigital.fgv.br/ojs/index.php/rae/article/view/30330/29171>. Acesso em: 16 fevereiro 2018. 
MUHR, Ernst. Os Critérios de julgamento das licitações. 1986. Disponível em: <http://rae.fgv.br/sites/rae.fgv.br/files/artigos/10.1590_S0034-75901986000200002.pdf>. Acesso em: 19 fevereiro 2018.

PACHECO, Regina Silvia. Administração pública nas revistas especializadas - Brasil, 1995 2002.2003 .2 Disponível em: <http://bibliotecadigital.fgv.br/ojs/index.php/rae/article/view/37551/36315>. Acesso em: 18 fevereiro 2018.

PAULA, Ana Paula Paes de. Administração pública brasileira entre o gerencialismo e a gestão social. $2005 . \quad$ Disponível em: <http://bibliotecadigital.fgv.br/ojs/index.php/rae/article/view/37088/35859>. Acesso em: 17 fevereiro 2018.

PAULA, Ana Paula Paes de. Cooperação e inovação na gestão pública: o caso da saúde. 2007. Disponível em: <http://bibliotecadigital.fgv.br/ojs/index.php/rae/article/view/36911/35681>. Acesso em: 20 fevereiro 2018.

PROPLADI.UNIVASF.EDU.BR. Atribuições. 2018. Disponível em: <http://www.propladi.univasf.edu.br/?page_id=33>. Acesso em: 22 março 2018.

PROPLADI.UNIVASF.EDU.BR. Estrutura Organizacional. 2018. Disponível em: <http://www.propladi.univasf.edu.br/?page_id=23>. Acesso em: 22 março 2018.

PT.WIKIPEDIA.ORG. Universidade Federal do Vale do São Francisco. 2018. Disponível em: <http://pt.wikipedia.org/wiki/Universidade_Federal_do_Vale_do_S\%C3\%A3o_Francisco>. Acesso em: 20 março 2018.

ROBLES, Léo Tadeu; FISCHMANN, Adalberto A. Contratos de gestão no estado de São Paulo o caso das empresas estatais não-financeiras. 1995. Disponível em: <http://bibliotecadigital.fgv.br/ojs/index.php/rae/article/view/38260/36975>. Acesso em: 14 fevereiro 2018.

SANO, Hironobu; ABRUCIO, Fernando Luiz. Promessas e resultados da nova gestão pública no Brasil: o caso das organizações sociais de saúde em São Paulo. 2008. Disponível em: $<$ http://bibliotecadigital.fgv.br/ojs/index.php/rae/article/view/36670/35448>. Acesso em: 25 fevereiro 2018.

SCHOMMER, Paula Chies. Gestão pública no Brasil: notícias do teatro de operações. 2003. Disponível em: <http://bibliotecadigital.fgv.br/ojs/index.php/rae/article/view/37554/36318>. Acesso em: 22 fevereiro 2018.

UNIVASF.EDU.BR. A Univasf. $2014 . \quad$ Disponível em: <http://www.univasf.edu.br/acessoainformacao/a_univasf.php>. Acesso em: 14 março 2018.

UNIVASF.EDU.BR. Institui Lei n. ${ }^{\circ}$ 10.473, de 27 de junho de 2002. 2002. Disponível em: <http://www.univasf.edu.br/acessoainformacao/arquivos/lei_10473.pdf >. Acesso em: 15 março 2018. 
ANEXO A - Lista de Artigos

\begin{tabular}{|c|c|c|c|}
\hline & Ano & Periódico & Título do Artigo \\
\hline A1 & 1986 & RAE & Os Critérios de Julgamentos das Licitações. \\
\hline A2 & 1993 & RAE & $\begin{array}{l}\text { Reforma administrativa nos anos 90: o caso da prefeitura } \\
\text { municipal de São Paulo. }\end{array}$ \\
\hline A3 & 1995 & RAE & $\begin{array}{l}\text { Contratos de gestão: contradições e caminhos da } \\
\text { administração pública. }\end{array}$ \\
\hline A4 & 1995 & RAE & $\begin{array}{l}\text { Contratos de gestão no estado de São Paulo o caso das } \\
\text { empresas estatais não-financeiras. }\end{array}$ \\
\hline A5 & 1999 & RAE & $\begin{array}{l}\text { A efetividade dos contratos de gestão na reforma do } \\
\text { estado. }\end{array}$ \\
\hline A6 & 2002 & RAE & A inovação presente na administração pública brasileira. \\
\hline A7 & 2002 & RAE & O legado de Celso Daniel para a gestão pública. \\
\hline A8 & 2003 & RAE & $\begin{array}{l}\text { Administração pública nas revistas especializadas - } \\
\text { Brasil, 1995-2002. }\end{array}$ \\
\hline A9 & 2003 & RAE & Gestão pública no Brasil: notícias do teatro de operações. \\
\hline A10 & 2005 & RAE & $\begin{array}{l}\text { Administração pública brasileira entre o gerencialismo e a } \\
\text { gestão social. }\end{array}$ \\
\hline A11 & 2006 & RAE & $\begin{array}{l}\text { As pedras e as flores do caminho: os percursos da gestão } \\
\text { pública no Brasil. }\end{array}$ \\
\hline $\mathbf{A 1 2}$ & 2007 & RAE & Cooperação e inovação na gestão pública: o caso da saúde. \\
\hline A13 & 2008 & RAE & $\begin{array}{l}\text { Promessas e resultados da nova gestão pública no Brasil: } \\
\text { o caso das organizações sociais de saúde em São Paulo. }\end{array}$ \\
\hline A14 & 2011 & RAE & $\begin{array}{l}\text { Políticas de Governo Eletrônico no Brasil: Contexto, } \\
\text { Gestão de Tic e Resultados. }\end{array}$ \\
\hline $\mathbf{A 1 5}$ & 2012 & RAE & $\begin{array}{l}\text { Incentivos governamentais em PPP: uma análise por } \\
\text { opções reais. }\end{array}$ \\
\hline A16 & 2013 & RAE & O estado da arte da Gestão Pública. \\
\hline $\mathbf{A 1 7}$ & 2018 & RAE & Desafios da gestão no campo social. \\
\hline
\end{tabular}

\section{Como citar este artigo (Formato ABNT):}

MAIA, Nathallia Barbosa Alencar; COELHO, Tâmara Rodrigues; SILVA, Bruno Cezar. Compras Públicas e Apoio Logístico na UNIVASF: Um Estudo Bibliométrico. Id on Line Rev.Mult. Psic., 2018, vol.12, n.42, p. 470-485. ISSN: 1981-1179.

Recebido: 22/09/2018;

Aceito: 29/09/2018 